DOI: https://doi.org/10.14232/actahisp.2020.25.53-64

\title{
LOLA BOTKA, LA FUNDADORA HÚNGARA DEL BALLET NACIONAL CHILENO
}

\section{GABRIELLA THOMÁZY}

Universidad Nacional de Servicio Público, Hungría

\begin{abstract}
Resumen: En 1945 nació el Ballet Nacional Chileno, hoy también conocido como BANCH. En 2020 se celebra el 75 aniversario de este instituto, con cuya fundación se iniciaba una época dorada para el ballet nacional, cuyo prestigio llegaría a los Estados Unidos, Argentina y Canadá. Muy pocos saben que en la historia del BANCH tuvo un papel importante una húngara, Lola Botka que nació en el año 1910 en Budapest y que, junto a su esposo Ernst Uthoff, fue fundadora del Ballet Nacional Chileno. El presente estudio tiene como objetivo principal contar la historia de la famosa bailarina que tuvo una gran influencia en el ballet profesional de Chile.

Palabras Claves: Lola Botka, Hungría, Chile, ballet, BANCH, migración húngara.
\end{abstract}

Abstract: The Chilean National Ballet was born in 1945, today also known as BANCH. This institute is celebrating its 75 th anniversary this year. The golden age of the national ballet started with its foundation, and its prestige would even reach the United States, Argentina, and Canada. However, it is not well known that a Hungarian, Lola Botka, born in Budapest in 1910, and her husband, Ernst Uthoff played an essential role in the history of $\mathrm{BANCH}$ and were the founders of the Chilean National Ballet. The main objective of this study is to tell the story of the famous dancer, Lola Botka, who had a significant influence on professional ballet in Chile.

Keywords: Lola Botka, Hungary, Chile, Ballet, BANCH, Hungarian Migration.

\section{Introducción}

Lola Botka fue una de los fundadores del Ballet Nacional Chileno junto a su esposo, el alemán Ernst Uthoff. Ambos sentaron las bases de la danza en Chile al fundar en 1945, bajo el alero de la Universidad de Chile, el Ballet Nacional Chileno, la primera compañía profesional del país a la que estuvo ligada durante más de seis décadas (Constenla, 2006). En la historia del instituto reconocido mundialmente, que en 2020 celebra su $75^{\circ}$ aniversario, tuvo un rol importante el matrimonio Botka-Uthoff. El presente estudio tiene como objetivo principal presentar la vida de Lola Botka, quien nunca retornó a su país natal y falleció en 2006 a la edad de 96 años en Chile, y su influencia en la cultura artística chilena. El estudio se realizó recopilando información de publicaciones, libros, una película documental, además de entrevistas personales con húngaros radicados en Chile1.

\footnotetext{
${ }^{1}$ Quiero agradecer la ayuda y el apoyo de Krisztina Tar (fundadora y directora de la Asociación Artística Folclórica Húngara Duna), de Zsófia Törey (directora de la Asociación Artística
} 
Lola Botka, la fundadora húngara del Ballet Nacional Chileno

\section{Húngaros en Chile}

Actualmente no hay mucha información acerca de la colonia húngara en Chile y su historia. Es importante destacar que en otros países de la región latinoamericana varios húngaros formaron parte de la historia local, como por ejemplo Juan Czetz (en húngaro: János Czetz) en Argentina, uno de los principales organizadores y a su vez el primer director del Colegio Militar de la Nación. Otro ejemplo es Francisco José Debali (en húngaro: Ferenc József Debály), compositor de la música del Himno Nacional de Uruguay y posiblemente también la del Himno Nacional de Paraguay (Szabó, 1982: 244-247). Un último sería el traductor, lingüista y profesor Paulo Rónai (en húngaro: Pál Rónai) en Brasil, traductor de más de 100 libros a portugués y ganador de varios premios (Spiry, 2009; Guerini, 2006).

El destino principal de los inmigrantes húngaros fueron los EE.UU. y América del Sur fue elegido como una segunda opción. Desde el principio de la década de 1920, una cantidad más significativa de húngaros comenzó a llegar al continente sudamericano debido a las cuotas de migración de los EE.UU. (Ley de cuotas: 1921, 1924 y 1929) que querían mantener lejos a los inmigrantes "malos", es decir, a los de Europa Central y Oriental, a los rusos y a los judíos y por tanto a los húngaros también (Son-Thierry y Weil, 2010: 45-78; Frank, 2016: 27-39). Los primeros húngaros llegaron a Chile en el siglo XVIII, (principalmente jesuitas, por ejemplo Márton Herre en 1724 y Márton Hedry en 1748), sin embargo, el país andino no fue popular entre los inmigrantes húngaros por la larga distancia desde el Atlántico, además por el difícil acceso por los Andes. Es por eso que en 1920 el número de la colonia húngara no superaba los 150 integrantes y en 1936 llegó a alcanzar los 600 miembros (Torbágyi, 2004: 175-193).

El máximo número de la comunidad húngara según las estimaciones hubiera podido alcanzar alrededor de 8-12 mil personas en la década de los sesenta (Torbágyi, 2004: 194). Actualmente cerca de dos mil húngaros viven en Chile, siendo la segunda comunidad húngara más pequeña dentro de la región después de la de Perú2. Mientras a Brasil, Argentina y Venezuela llegaron húngaros de diferentes grupos sociales, Chile preferentemente fue elegido por individuos o familias mayormente de un estatus social alto (Torbágyi, 2004: 175-195). Muchos de ellos tuvieron un rol importante en la industria chilena, principalmente en la industria minera, como por ejemplo la familia Kemeny que fue dueña de la famosa mina de San José donde quedaron atrapados los 33 mineros el 5 de agosto de $2010^{3}$.

Folclórica Húngara Duna) y de Aranka Lillo Botka, nieta sobrina de Lola Botka, bailarina de la Asociación Artística Folclórica Húngara Duna o más conocida como Grupo de Danza Duna, en húngaro: Duna Táncegyüttes (Dunafolk, 28-09-2020).

${ }^{2}$ Brasil: 70 mil; Argentina: 40 mil; Venezuela: 4500; Uruguay: 3500; Chile: 2000; Perú: 1600 (Szondi- Baranyi-Mészáros y Szabó, 2009: 610).

${ }^{3}$ Jorge Kemeny llegó a Chile en 1957 y dedicó toda su vida a la industria minera e incluso llegó a ser Consejero General de la Sociedad Nacional de Minería. En 1981 compró las minas de San José 


\section{La historia de Lola Botka}

\subsection{Desde Hungría a Chile}

No sabemos mucho de la vida de Lola Botka en Hungría, se sabe que nació en 1910 en Budapest, más probablemente en una familia de una buena situación económica, pero después habrían perdido su fortuna y Lola tuvo que trabajar desde muy joven, por lo tanto no terminó sus estudios. Ella fue alumna de la escuela de Szentpal, considerado como uno de los mejores centros entre las 30 escuelas de danza que dedicaban el movimiento alemán "ausdruckstanz" en el país, movimiento que quería revolucionar el ballet tradicional (Hézső, 2014: 24-33; Corporación Danza Chile, 09-08-2020). En 1928, a los 18 años de edad, hizo su primera aparición como bailarina profesional en el Festival de Múnich donde presentó su propia obra Él, ella y el otro. El éxito fue inmediato, por lo que Kurt Jooss (el ballet Jooss fue una de las más notables compañías de la época) la contrató. Esa misma noche, en el público, se encontraba uno de los integrantes del ballet Jooss, Ernst Uthoff, quien se convertiría no solo en su futuro compañero de trabajo sino también en el amor de su vida (Memoria chilena, artículo 96458, 10-08-2020).

La compañía de Jooss llegó a reunir a los mejores bailarines europeos de la década de los treinta, a quienes seleccionaba en concurridas audiciones. Jooss alcanzó notoriedad en 1932 cuando obtuvo el primer lugar en el Congreso Internacional de la Danza de París con La mesa verde, una coreografía de gran originalidad que formulaba una severa crítica al funcionamiento de la Liga de las Naciones. La Segunda Guerra Mundial empujó a la compañía de Jooss a establecerse en Londres. Lola y Ernst vivieron 11 años juntos antes de contraer matrimonio, una costumbre un tanto moderna para la época, pero finalmente terminaron casándose en Inglaterra cuando comenzó la guerra. La compañía canceló su gira en los EE.UU. y decidieron viajar a Sudamérica junto a algunos miembros del grupo, incluyendo a Lola Botka, a Ernst Uthoff y a Rudolf Pescht. El Ballet Jooss debutó en Chile en el Teatro Municipal de Santiago, en la temporada de invierno del año 1940 que también contó con la presencia del American Ballet. El estilo de Jooss despertó inmediato interés en Chile (Memoria chilena, artículo 96640, 12-08-2020; Memoria chilena, artículo 96458, 10-08-2020; Corporación Danza Chile, 2006).

y San Antonio con contenido de cobre con oro, ubicadas en la tercera región del país, cerca de Copiapó (Norte de Chile) y fundó la Compañía Minera San Esteban Primera, bautizada con el nombre del primer rey de Hungría. Jorge Kemeny logró hacer su fortuna gracias a los distintos yacimientos mineros. Falleció a sus 72 años y en su testamento señaló que dividiría su imperio entre Marcelo y Emérico, sus dos hijos (Jancsó, 2018: 69-79; Informe Mina San José, 2011).

Acta Hispanica 25: 53-64, 2020, ISSN 1416-7263, e-ISSN 2676-9719 | 55 


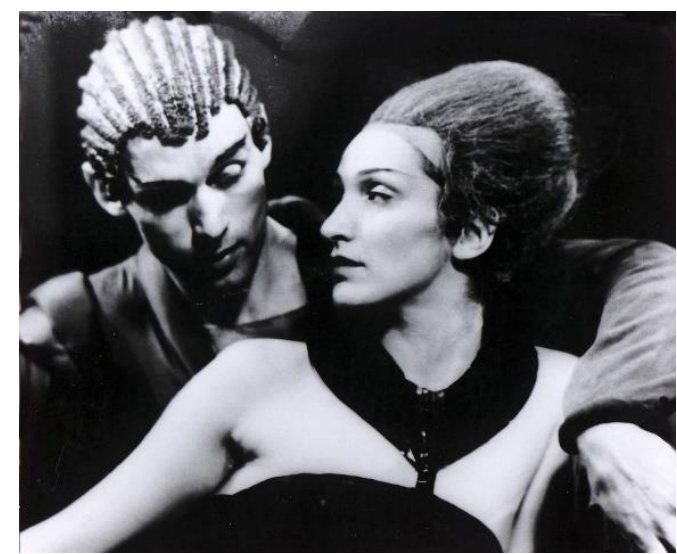

Ilustración 1. Ballet Nacional Chileno Lola Botka y Ernst Uthoff (Aguilar, 2013)

\subsection{La fundación del Ballet Nacional Chileno}

En el siglo XIX algunas compañías europeas llegaron a Chile y mostraron a los santiaguinos las creaciones del romanticismo, así el público chileno tuvo su primera visión de lo que era el arte del ballet, pero el país prefería la ópera y redujo el ballet a una dependencia y le prestaba un papel secundario dentro de su escénica. Desde el año 1920, varias escuelas privadas empezaron a funcionar, pero principalmente para una élite (Montecinos, 2002a: 7-27). Hasta el año 1941 no existía en Santiago ningún coreógrafo o director capaz de crear sobre bases realmente inconmovibles y sólidas, una tradición y movimiento de danza clásica y académica. Los esfuerzos de los profesores antes de 1940 no lograron cristalizarse en una compañía estable subvencionada por la Universidad de Chile o por la Municipalidad de Santiago y siempre se circunscribieron a círculos de aficionados. La fundación de un grupo estable como el Ballet Nacional Chileno se produjo como una culminación lógica de los hechos histórico-artísticos (Montecinos, 2002b: 37-53).

Desde la perspectiva de la historia del ballet en Chile, el visitante más importante de todos fue Kurt Jooss y su célebre compañía alemana que había adquirido fama internacional al ganar el Concurso del Congreso Internacional de la Danza en París, llegando a Chile en el año 1940. De forma visionaria, Andrée Haass ${ }^{4}$, bailarina notable en el medio artístico nacional, se acercó a Uthoff para pedirle que se quedara en Chile a fin de crear y desarrollar un estudio serio de danza, lo que Uthoff no aceptó por fidelidad a Kurt Jooss y continuaron su gira por Sudamérica; no obstante, un año más tarde, la compañía de Jooss se disolvió por la guerra y el maestro Uthoff aceptó la

\footnotetext{
${ }^{4}$ Andrée Haass (1908-1981) de ascendencia sueca era profesora titulada en el Instituto de Jacques Dalcroze de Ginebra y la única representante en Chile de este método (Montecinos, 2002b: 37-53).
} 
proposición y las autoridades del Instituto de Extensión Musical de la Universidad de Chile. Para crear un cuerpo estable del ballet en el país junto a Ernst Uthoff contrataron también a Lola Botka y al primer bailarín del grupo Jooss, Rudolf Pescht. En mayo de 1941 los tres volvieron a Santiago (Saez, 1993: 16-17).

El inicio del trabajo en Chile no fue fácil. No existían bailarines profesionales ni tampoco los espacios para enseñar. Así lo recuerda Lola Botka:

\section{[...] y preguntamos dónde estaban los bailarines y nos dijeron que no había y que creían que nosotros los íbamos a formar, pero entonces tienen que esperar, ¿y dónde está la sala?, no tenemos sala, entonces buscamos sala...y pusimos un aviso en el diario que educamos jóvenes, hombres para bailarines [...] (Cifuentes, 2007: 66).}

Primero crearon una escuela de baile con el respaldo de la Universidad de Chile cuya primera clase tuvo lugar el 7 de octubre de 1941. La escuela formó a bailarines y el mismo elenco de alumnos prepararon funciones, mientras que Lola Botka y Rudolf Pescht preparaban a las futuras bailarinas chilenas en el sistema Jooss y Ernst Uthoff realizaba el triple papel de director artístico, coreógrafo y profesor (Saez, 1993: 16-17; Montecinos 2002a: 7-27). El 18 de mayo de 1945, a las 18:30 horas, el Instituto de Extensión Musical de la Universidad de Chile ofreció una representación extraordinaria, fuera de abono, con el estreno del ballet Coppelia (Montecinos 2002b: 37-53).

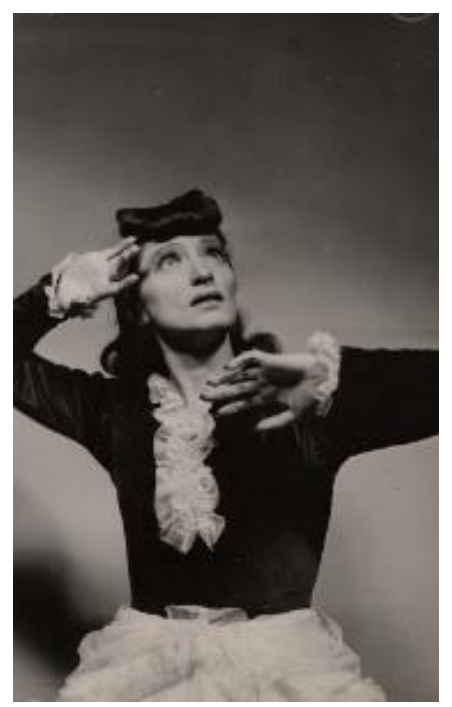

Ilustración 2. Ballet Nacional Chileno, Coppelia, Lola Botka en 1945 (Centro DAE, 05-08-2020) 
La Orquesta Sinfónica de Chile, dirigida por Víctor Tevah ${ }^{5}$, y con el húngaro Zoltan Fischer ${ }^{6}$ como primera viola, acompañó al ballet. Finalmente, el 15 de agosto de 1945 nació la primera compañía de danza de Chile con el nombre de Ballet Nacional Chileno. Con el estreno de Coppelia, de Leo Delibes, y con la coreografía de Uthoff, se marcó el comienzo de la historia del ballet chileno que hasta ese momento pertenecía a elencos extranjeros o academias privadas (Saez, 1993: 16).

\subsection{La vida de Lola Botka en Chile}

Ernst Uthoff y Lola Botka formaron la primera generación de los bailarines y coreógrafos locales, y crearon numerosas obras que llevaban la fama de BANCH al extranjero también. La coreografía de Uthoff más conocida fue la obra Carmina Burana (1953), basada en la partitura de Carl Orff, dándole a la compañía fama internacional convirtiéndose en parte del repertorio esencial de la historia de la danza en Chile. Además, querían que los chilenos conocieran el arte del ballet, aunque preferían que la gente asistiera al teatro. En un país largo como Chile, debido a las grandes distancias, no había posibilidad para eso, debido a ello, desde 1946, organizaron giras en verano dentro de Chile y llevaron el ballet en carpas o escenarios al aire libre, de esta forma había más ambiente de cultura para el pueblo lejos de la capital. En alrededor de la mitad de las 80 funciones que realizaron al año, estuvieron incluidas giras al norte o al sur del país y, desde 1956, al extranjero. En 1956 el Ballet Nacional Chileno realizó su primera gira en el extranjero, actuando en el Teatro del S.O.D.R.E. en Montevideo y en el Colón de Buenos Aires, ciudades a las que volvió en los años 1960, 1962 y 1963. En el año 1958 visitó Lima y en 1964 Puerto Rico. Debutó, además, en el Lincoln Center de Nueva York y viajó a Canadá. El director de la Orquesta Sinfónica de Chile, Víctor Tevah, acompañó el ballet durante cada una de las giras (Corporación Danza Chile, 2006; Memoria chilena, artículo 96637, 10-08-2020; Canepa, 1985).

Lola Botka y su marido, Ernst Uthoff, formaron una familia y tuvieron dos hijos Michael y Andras. Michael siguió los pasos de sus padres y se convirtió en un bailarín,

\footnotetext{
${ }^{5}$ Víctor Tevah (1912-1988), nacido en Grecia, llegó a Chile en 1912, siendo inscrito como ciudadano chileno. En 1920 se trasladó a Santiago para realizar estudios de música entre 1921 y 1930, especializándose en violín y música de cámara. Su labor rebasó las fronteras de Chile. Se le invitó a dirigir por toda América Latina (Memoria chilena, artículo 97013, 09-08-2020).

${ }^{6}$ Zoltan Fischer (1910-1970), nacido en Hungría en 1910, realizó sus primeros estudios musicales en el Conservatorio Real de Budapest. A los diecinueve años llegó a Chile, ingresando en el Conservatorio Nacional de Música donde fue alumno del maestro Werner Fischer. En este plantel alcanzó rápidamente las más altas calificaciones graduándose como concertista en viola. En 1940 junto a René Amengual, Juan Orrego-Salas y Alfonso Letelier, Zoltan Fischer y su esposa la pianista Elena Waiss, también clavecinista de la Sinfónica de Chile, fundaron la Escuela Moderna de Música, vigorosa entidad musical donde se han formado músicos chilenos de excelencia (Editorial, C, 2020: 83-85).
} 
coreógrafo y director artístico reconocido internacionalmente, su desarrollo laboral principalmente fue en EE.UU. (Cary Ballet, 07-08-2020). Andras es ingeniero comercial de la Universidad de Chile; Máster y Doctor en Economía de la Universidad de California, Berkeley, y ha sido asesor regional de la Organización Internacional del Trabajo (OIT), la Comisión Económica para América Latina y el Caribe (CEPAL) entre otros (Consejo Consultivo Previsional, 07-08-2020).

Lola Botka tenía un hermano, Pablo Botka (en húngaro: Pál Botka), que nació en 1909 en Budapest, pero no alcanzó a arrancar de la guerra e incluso quedó encerrado varios años en prisión durante el comunismo. Finalmente, después de su liberación, con la ayuda de la Cruz Roja, llegó a Chile en 1957 y encontró un apoyo fundamental en su hermana para establecerse en el país. Pablo Botka, que fue deportista toda su vida, estudió educación física y practicaba varias disciplinas antes de la Segunda Guerra Mundial. También adquirió fama en Chile, se le conoció como "el padre del balonmano chileno". En efecto Pablo Botka llevó a Chile este deporte desconocido y en el año 1971 la Dirección General de Deportes y Recreación (DIGEDER) le contrató para iniciar la difusión del balonmano en Chile de forma oficial, bajo el título de "Programador Nacional de Handball" (Feuchtmann, 2014: 71-80).

A Lola Botka no le gustaba hablar de su vida en su país natal, nunca más volvió a Hungría, puede ser que por las historias que escuchó de su hermano o de otras personas, pero no quiso volver al igual que muchos de los húngaros en Chile, siendo generalmente entre las razones que más se esgrimen la familia local, la distancia y que la vida cambió radicalmente en Hungría (Hézső, 2014: 24-33).

Uthoff se retiró de la actividad en 1966; en el año 1984 obtuvo el Premio Nacional de las Artes y murió en 1993. No conocemos exactamente la fecha del retiro de Lola Botka del Ballet Nacional Chileno, pero tras terminar la danza activa, continuó asistiendo regularmente a las funciones de su segunda familia, la compañía a la que siempre se sintió estrechamente ligada. La última vez que se la vio en una función fue para el reestreno de Carmina Burana, en 2004. Lola Botka falleció en 2006 a los 96 años a causa de una neumonía agravada por la avanzada edad de la artista y por el hábito de fumar, que nunca pudo dejar del todo (Memoria chilena, artículo 96637, 10-08-2020; "Murió Lola Botka...", 2006).

[...] Mi madre fue una persona agradecida de la vida, por eso nos dejó una carta en la que nos pidió que en su partida se cantara el tema "Gracias a la vida" (de Violeta Parra), dijo András. Agregó que "ella empezó a despedirse en 1996, cuando ya estaba delicada de salud, pero su gran empuje siempre hacía que volviera a recuperarse porque era como una pila recargable. El ballet fue la razón de vivir de mis padres, los creadores del BANCH [... (Constenla, 2006). 
Lola Botka, la fundadora húngara del Ballet Nacional Chileno

\subsection{El legado de Lola Botka}

Durante los años que participó en la compañía de Kurt Jooss, Lola Botka fue reconocida por sus notables interpretaciones: destacó como bailarina de carácter en personajes tales como "la vieja madre" en La mesa verde, obras que dio inicio al éxito del Ballet Jooss. A lo largo de su carrera, se la recuerda por interpretaciones tan diversas como Alotria, El Hijo Pródigo y Coppelia (Memoria chilena, artículo 96458, 10-08-2020).

La labor de Lola Botka influyó fuertemente en las bailarinas chilenas que aprendieron de ella, en el escenario y en sus clases, el dominio y lenguaje de las manos. Se caracterizó por su facilidad para la interpretación y, sobre todo, por el dominio del gesto. Su disciplina la llevó a convertirse en uno de los referentes de la danza chilena, desarrollando importantes labores dentro de la creación de personajes. Creó innumerables papeles para el Ballet Nacional Chileno, dando siempre un ejemplo importante de dinamismo y disciplina (Montecinos, 2002b: 37-53; Memoria chilena, artículo 96458, 10-08-2020).

En la historia del ballet chileno hay otros húngaros y de algún modo, casi todos tienen relación con Lola Botka. Charles Zsedenyi (en húngaro: Károly Zsedényi, nacido en 1910, Gyenesdiás, Hungría,) notable maestro de ballet, coreógrafo y pianista húngaro que llegó a Chile en 1952 como refugiado. Zsedenyi participó en una de las coreografías de Lola Botka, el Czardas en la Noche, además fue fundador del Ballet Experimental chileno en el año 1954, compañía privada de ballet, de muy buen nivel, subvencionada por el mismo Zsedenyi. Charles Zsedenyi trajo con él al bailarín húngaro Janos Bachora (en húngaro: János Bachora), que ocupaba el cargo de primer bailarín de su compañía y, posteriormente, también del Ballet de Arte Moderno (Vásquez, 2017: 13-14; Hézső, 2014: 24-33).

Ivan Nagy, nacido en 1943 en Debrecen, una ciudad ubicada en el extremo oriental de Hungría, tras una prolífica carrera como bailarín -que incluyó su paso por el Ballet Nacional de Washington, el Ballet de la Ciudad de Nueva York y el American Ballet Theatre-, se retiró en 1978 cuando tenía solo 35 años, y en 1981 se instaló en Chile para dirigir el Ballet de Santiago (fundado en 1958). Lola Botka apoyó fuertemente su postulación como director artístico, rol que desempeñó hasta 1986 y que después retomaría en otro periodo: desde 1996 a 1999. Ivan Nagy quería volver a Chile por otro periodo, pero murió repentinamente en el año 2014 (Góngora, 2014; Hézső, 2014: 24 33; En memoria de Ivan Nagy, 2014).

Aunque por poco tiempo, Imre Dózsa, otro húngaro, fue director artístico del mismo instituto entre 1989-1991 (Magyar színháżứvészeti lexikon, 12-08-2020). Es interesante que fue el Ballet de Santiago el que en 1992 viajó a Hungría y no el BANCH. El Ballet de Santiago, cuya presentación fue el programa más importante del Festival de Primavera de Budapest, debutó así en el escenario de la Ópera Estatal de Hungría (Halász, 2013). 
Lola Botka incluso tuvo una influencia en la comunidad húngara del siglo XXI. En 2016 se fundó la Asociación “Artística Folclórica Húngara Duna” (Dunafolk, 09-08-2020) en Santiago, siendo el primer grupo de baile húngaro en la historia de la colonia y su fundadora, Krisztina Tar, se sintió inspirada por la famosa bailarina al momento de fundar la asociación. En el Grupo de danza Duna bailan húngaros y chilenos que quieren conocer esta cultura, siendo también una de las bailarinas del grupo la nieta de Pablo Botka, Aranka (sobrina nieta de Lola Botka), así la familia Botka, de algún modo volvió a sus raíces húngaras.

\section{Conclusión}

El año 2020 es un año muy importante para la historia del ballet chileno, ya que se conmemora el 110 aniversario del nacimiento de Lola Botka y el 75 aniversario de la fundación del Ballet Nacional Chileno. Lola Botka, bailarina de origen húngaro, tuvo una trayectoria muy larga antes de llegar a Chile, inició su viaje en Budapest, la capital de Hungría, recorriendo muchos países, como por ejemplo Alemania, Francia, Inglaterra y varios en América del Sur, por lo que con una experiencia tremenda llegó a Santiago para formar la nueva generación del ballet chileno junto con su marido.

La vida de Lola Botka podría ser un ejemplo para todas las personas que busquen un nuevo futuro lejos de su país natal, que quieren contribuir y dar algo positivo al país receptor e inspirar a otras personas con su trabajo, sería un aspecto interesante no solo para los húngaros. En este artículo hemos nombrado a varios húngaros que, por algún motivo, tenían relaciones personales con Lola Botka en Chile o, simplemente, se inspiraron en su historia. Todos estos húngaros tienen algo en común, decidieron elegir Chile como su nueva patria, lejos de Hungría. Lamentablemente, no tenemos mucha información de los húngaros que llegaron a Chile, ya que el tema no ha despertado el interés de los investigadores y justo por eso sería importante rescatar las historias personales antes de que estas se olviden completamente.

\section{Referencias bibliográficas}

Aguilar, Carmen (2015). La obsesión por la danza y la música que cambió Chile. 24 horas.cl. Asequible en: https://www.24horas.cl/tendencias/espectaculosycultura/la-obsesion-porla-danza-y-la-musica-que-cambio-chile-1580078, fecha de consulta: 05-08-2020.

Asociación Artística Folclórica Húngara Duna. Duna Folk. Asequible en: https://www.dunafolkchile.com/sobre-nosotros, fecha de consulta: 09-08-2020.

Bio Michael Uthoff. Cary Ballet. Asequible en: https://www.caryballet.com /biomichaeluthoff.html, fecha de consulta: 07-08-2020.

Cifuentes, María José (2007). Historia social de la danza en Chile. Visiones, escuelas y discursos 1940-1990. Santiago: LOM Ediciones 
Lola Botka, la fundadora húngara del Ballet Nacional Chileno

Canepa Guzmán, Mario (1985). El Teatro Municipal en sus 125 años de sufrimientos y esplendor. Santiago: [sin editor].

Consejo Consultivo Previsional. Andras Uthoff Botka. Asequible en:

https://www.consejoprevisional.cl/integrantes.php, fecha de consulta: 07-08-2020.

Constenla, Nury (2006). Emotivo adiós a la bailarina Lola Botka, fundadora del Banch.

UChile.cl. Asequible en: https://www.uchile.cl/noticias/39191/emotivo-adios-a-labailarina-lola-botka-fundadora-del-banch, fecha de consulta: 01-08-2020.

Editorial, C. (2020). Zoltan Fischer, 1910-1970. Revista Musical Chilena, 24(112). 83-85.

En memoria de Ivan Nagy, en el día internacional de la danza. Teatro Nescafe de las Artes, 29 de 04 de 2014. Asequible en: https://teatro-nescafe-delasartes.cl/en-memoria-deivan-nagy-en-el-dia-internacional-de-la-danza/, fecha de consulta: 10-08-2020.

Ernst Uthoff (1904-1993). Memoria chilena, articulo 96637. Asequible en: http://www.memoriachilena.gob.cl/602/w3-article-96637.html, fecha de consulta: 10 08-2020.

Feuchtmann Pérez, Inga Silke (2014). La historia del balonmano en Chile. Memoria para optar al título de periodista, Universidad de Chile: Santiago. Asequible en: http://repositorio.uchile.cl/bitstream/handle/2250/132840/Tesis_Historia_Balonman o_Chile.pdf?sequence $=1$ \&isAllowed $=\mathrm{y}$, fecha de consulta: 05-08-2020.

Frank, Tibor (2016). Be- és kivándorlás a magyar történelemben. Kisebbségkeutatás, 25(1). 27-39.

Góngora, Loreto (2014). Ivan Nagy (1943-2014). CentroDae. Asequible en: http://www.centrodae.cl/wp_cdae/?p=4878, fecha de consulta: 10-08-2020.

Guerini, Andréia (2006). Paulo Rónai. Asequible en: https://dicionariodetradutores.ufsc.br /pt/PauloRonai.htm, fecha de consulta: 10-08-2020.

Halász, Tamás (2013). Nagy pálya. Fidelio. Asequible en: https://fidelio.hu/tanc/nagypalya-54442.html, fecha de consulta: 25-08-2020.

Hézső, István (2014). Botka Lola a nagy ismeretlen. Parallel, 31. 24-33.

Informe final de comisión investigadora de la Cámara de Diputados sobre derrumbe en mina San José Ciperchile online, 20 de enero de 2011. Asequible en: https://ciperchile.cl /wp-content/uploads/Informe-final-de-comisi $\% \mathrm{C} 3 \% \mathrm{~B} 3 \mathrm{n}$-investigadora-de-la-C $\% \mathrm{C} 3 \%$

A1 mara-de-Diputados-sobre-derrumbe-en-mina-San-Jos\%C3\%A9.pdf, fecha de consulta: 25-08-2020.

Jancsó, Katalin (2018). Húngaros en la industria minera de Chile. En: Domingo LilónMaté Deák (eds.). Encuentros. Europa-Iberoamérica en un mundo globalizado. Libro homenaje al Prof. Dr. Ferenc Fischer. Pécs: Fakultás. 69-79.

Kurt Jooss. Memoria chilena, artículo 96640. Asequible en: http://www.memoriachilena.gob.cl /602/w3-article-96640.html, fecha de consulta: 12-08-2020. 
Lola Botka (1910-2006). Memoria chilena, artículo 96458. Asequible en: http://www.memoriachilena.gob.cl/602/w3-article-96458.html, fecha de consulta: 10 08-2020.

Magyar szinházmüvészeti lexikon. Dózsa Imre. Asequible en: http://mek.niif.hu /02100/02139/html/sz05/242.html, fecha de consulta: 12-08-2020.

Miembros de la Asociación Artística Folclórica Húngara Duna. Dunafolk. Asequible en: https://www.dunafolkchile.com/miembros-del-grupo, fecha de consulta:28-09-2020.

Montecinos, Yolanda (2002a). Historia del ballet en Chile. Revista Musical Chilena, 56. 7 27. DOI: $10.4067 /$ S0716-27902002005600002

Montecinos, Yolanda (2002b). El Ballet Nacional Chileno. Perspectiva histórica y humana. Revista Musical Chilena, 56. 37-53. DOI: 10.4067/S0716-27902002005600004

Murió Lola Botka, fundadora del BANCH. El Mercurio, 27 de noviembre de 2006. Asequible en: https://www.emol.com/noticias/magazine/2006/11/27/237333/muriolola-botka-fundadora-del-banch.html, fecha de consulta: 10-08-2020.

Saez, María Inés (1993). Una Década de Ballet en el Teatro Municipal de Santiago: 1982-1992. Santiago: Esso Editorial Los Ángeles.

Son-Thierry Ly - Weil, Patrick (2010). The antiracist origin of the Quota system. Social Research, 77(1). 45-78. DOI: 10.2307/40972243.

Spiry, Zsuzsanna Filomena (2009). Paulo Rónai, um brasileiro made in Hungary. Dissertação apresentada à Faculdade de Filosofia, Letras e Ciências Humanas da Universidade de São Paulo para obtenção do título de Mestre. DOI: 10.11606/D.8.2009.tde-18112009154021

Szabó, László (1982). Magyar múlt Dél-Amerikában (1519-1900). Budapest: Europa.

Szondi, Ildikó - Baranyi, Emese Zsuzsanna - Mészáros, János - Szabó, Henriette Éva (2009). A Latin-Amerikába kivándorolt magyarság demográfiai helyzete. Acta Universitatis Szegediensis, 72 (1-22). 601-613.

Torbágyi, Péter (2004). Magyarok Latin-Amerikában. Budapest: A Magyar Nyelv és Kultúra Nemzetközi Társasága.

Victor Tevah (1912-1988). Memoria chilena, articulo 97013. Asequible en: http://www.memoriachilena.gob.cl/602/w3-article-97013.html, fecha de consulta: 0908-2020.

Vásquez Bouffanais, Millaray (2017). La influencia rusa y soviética en la danza chilena durante el siglo XX. Observatorio Danza. Asequible en: http://www.observatoriodanza.cl /danza/wp-content/uploads / $\mathrm{Va} \% \mathrm{CC} \% 81$ squez-Millaray.-La-influencia-rusa-y-sovie $\%$ CC\%81tica-en-la-danza-chilena-durante-el-siglo-XX.pdf, fecha de consulta: 09-08-2020. 
Lola Botka, la fundadora húngara del Ballet Nacional Chileno

\section{Fotografías}

Ilustración 1. Ballet Nacional Chileno - Lola Botka y Ernst Uthoff. Aguilar, Carmen. La obsesión por la danza y la música que cambió Chile. 24 horas.cl. 13 de 02 de 2015. Asequible en: https://www.24horas.cl/tendencias/espectaculosycultura/la-obsesionpor-la-danza-y-la-musica-que-cambio-chile-1580078, fecha de consulta: 05-08-2020.

Ilustración 2. Ballet Nacional Chileno, Coppelia, Lola Botka en 1945. Centro DAE. Asequible en: http://www.centrodae.cl/wp_cdae/?p=3471, fecha de consulta: 05-082020.

\section{Video}

Corporación Danza Chile (2006). Fundadores del Ballet Nacional Chileno - Capitulo 1: Ernst Uthoff y Lola Botka. Asequible en: https://www.youtube.com/watch?v=NwcMaV2CSQ $\mathrm{w} \& \mathrm{t}=4 \mathrm{~s}$, fecha de consulta: 09-08-2020. 